\title{
Sizing Up Transport Poverty Alleviation: A Structural Equation Modeling Empirical Analysis
}

\author{
Li Jiang, Huiying Wen $(\mathbb{D}$, and Weiwei Qi $\mathbb{D}$ \\ School of Civil Engineering and Transportation, South China University of Technology, Guangzhou 510641, Guangdong, China \\ Correspondence should be addressed to Weiwei Qi; ctwwqi@scut.edu.cn
}

Received 25 March 2020; Revised 10 May 2020; Accepted 26 May 2020; Published 10 July 2020

Academic Editor: Ye Yu

Copyright (c) $2020 \mathrm{Li}$ Jiang et al. This is an open access article distributed under the Creative Commons Attribution License, which permits unrestricted use, distribution, and reproduction in any medium, provided the original work is properly cited.

\begin{abstract}
The aim of this paper was to systematically obtain the poverty reduction effects and diversified poverty alleviation paths of road infrastructure, to assist in the planning of transport poverty alleviation and rural revitalization in the concentrated contiguous poverty-stricken areas. The measurement methods for impact effects and paths of transport poverty alleviation have been scientifically proposed based on methods of transportation economics and transportation geography. Firstly, an overview of the interactive mechanism and processes by which road infrastructure investment influences poverty reduction has been offered, and the characteristics of poverty space and spatial coupling result of road infrastructure have been systematically obtained. The results show that about $70 \%$ of the district counties' road infrastructure and poverty rate are in a state of spatial coupling imbalance; the coordinated synchronous type is mainly distributed along the road network. Secondly, the structural equation model system has been formulated with variables that reflect transportation input in adjacent geographical units to consider spatial spillover effects. The results show that the direct poverty reduction effect of road infrastructure (0.105) is much lower than the indirect poverty reduction effect (0.830). Thirdly, empirical analysis at regional level of the concentrated contiguous poverty-stricken areas in China has been conducted. As a result, while addressing the limitations of previous studies, the poverty alleviation path that has been proposed also aims to catalyze actions to reduce the transport-related exclusion in poverty-stricken areas caused by the lack of access to basic facilities.
\end{abstract}

\section{Background}

Poverty is a global development problem and a practical problem. Antipoverty has become an important issue facing all mankind, especially developing countries, where poverty has seriously restricted the coordinated development of social economy [1]. One of the largest and most comprehensives surveys about poverty published to date is the "Voices of the Poor," which summarized 40,000 experiences of poor people from 50 different countries around the world. The findings of this report assert that poverty is perceived as consisting of many interlocking dimensions, in which lack of access to basic infrastructure, rural roads, and transportation is frequently pointed out as a remarkable factor [2]. In addition, evidence recently published by the World Bank has shown that the primary difference between those who have escaped chronic poverty and those are still trapped in it is not income, but access to essential services [3]. Transport is one of the main sectors; the Asian Development Bank (ADB) supports a reflection of the important role that transport plays in enabling economic development and poverty reduction $[4,5]$.

In the realm of transportation research, road infrastructure is frequently cited as a critical catalyst for regional social transformation and economic growth; it can generate payoffs for local development $[6,7]$. However, how the payoffs come into effect remains uncertain. Polzin categorized the impacts of road infrastructure on economy development into three types: direct, indirect, and secondary [8]. The direct impacts are those related to the improved service and accessibility; the indirect impacts are those related to mediating community responses and policy change; the secondary impacts are those related to social perception and individual behavioral changes. In this context, it is 
worthwhile to examine the pathways for the influence of the road infrastructure on the local economy and poor reduction using quantitative measurements.

As a multivariate statistical technique, structural equation modeling (SEM) can discover the direct or indirect relationships between exploratory variables and a dependent variable and then visualize the causal influencing pathways and medicating effect $[9,10]$. Previous pilot studies have indicated that SEM is suitable for social and economic studies, and it can deal with the problem of causality between public capital and output. However, rarely have studies applied SEM to investigate the relationships between the road infrastructure and economic development, as well as the transport poverty alleviation. The primary objective of this paper is to explore the relationships between the road infrastructure and regional economic development using SEM. In particular, analysis is conducted in the concentrated contiguous destitute areas of Yunnan in southwestern inland China.

The concentrated contiguous destitute areas of Yunnan located in southwestern China are shown in Figure 1. Among the 14 concentrated contiguous destitute areas in China, there are four in Yunnan, which are composed of 91 cities/counties. These regions, respectively, account for $65.89 \%$ and $12.50 \%$ of the total number of administrative units at the county level and the total number of contiguous areas in China.

The concentrated contiguous destitute areas of Yunnan are among the most underdeveloped hilly regions in China. Their socioeconomic conditions and road infrastructure construction are significantly lower than the national average. This region provides useful cases to study the pathway for the influence of the road infrastructure on the local economy among poverty-stricken areas with development.

Under these circumstances, this study aims to provide a comprehensive empirical evaluation of the impact that transportation development has on economic growth and poverty reduction, which can assist the planning of traffic poverty alleviation and rural revitalization in the contiguous poverty-stricken areas of Yunnan (in China). This paper differs from existing research in several aspects. First, an overview of the interactive mechanism and processes has been offered by which road infrastructure investment influences poverty reduction and the characteristics of poverty space and spatial coupling result of road infrastructure have been systematically obtained. Second, a structural equation model (SEM) has been built, which comprehensively considers the mutual relationship between transportation investment and poverty reduction; meanwhile, social capital, material capital, and geographical capital have been added as endogenous variables in the model system. Third, the model system has been formulated with variables that reflect transportation input in adjacent geographical units to consider spatial spillover effects. Fourth, empirical analysis at regional level of the concentrated poverty-stricken areas in China has been conducted. The poverty alleviation path that has been proposed aims to catalyze actions to reduce the transport-related exclusion in poverty-stricken areas caused by the lack of access to basic facilities (e.g., health, education, financial, and ecological facilities).

The remainder of this paper is structured as follows: Section 2 theorizes about the transport-region economic relationship. Then, the data sources and types are illustrated in Section 3, and the evaluation methods between road infrastructure and poverty rate are also applied. Section 4 mainly discusses the empirical results of research. Finally, this paper ends with some conclusions and discussion in Section 5 .

\section{Theorizing the Transport-Region Economic Relationship}

2.1. Literature Review. Previous studies linking the local economy to road infrastructure can be traced back to the last century. The potential contributions of the transportation sector to poverty reduction have been investigated in several countries and institutions since the late 1960s [11-20].

In recent years, the conceptualization and measurement of transport disadvantages have garnered even more attention, particularly from academics and decision-makers of the developed countries, for being considered as a key driver of social inclusion and social justice [21-26]. This phenomenon has been illustrated by a number of studies pointing out that accessibility constraints tend to deepen sociospatial inequalities leading to multidimensional deprivations and, eventually, poverty traps $[19,27]$. In this sense, accessibility, as the ultimate goal of most transportation, has been also proposed to be understood and planned as a fundamental human capability since it plays a central role in enabling people to meet their needs and promote healthy human flourishing [28-30]. Moreover, in spite of the increasing body of research dedicated to evaluating access to house facilities and healthcare services in rural China or low and middle income countries [31, 32], only few notable exceptions have been dedicated to quantitative evaluation of the overall accessibility poverty in such context [33-35].

Existing literature attempts to reveal the transport economic mechanisms using an econometric approach. These researches demonstrated the economic impact of transportation infrastructure investment through three pathways: (1) enhancing overall production productivity [36, 37], (2) accelerating technological spillovers across economic units [38, 39], and (3) reducing trade costs and enlarging sale spatial scope $[40,41]$.

Another branch of literature employs the classical statistical method to quantify the association between transportation infrastructure and the regional economy. An empirical analysis [42] showed that the impact of highway construction on population growth was weak in rural areas and strong in suburban areas. Guo proved that highway development, railway development, and railway investment all contributed positively to economic growth [43]. Iacono and Levinson pointed out that local road infrastructure and employment have no significant associations [7]. Yu found that road infrastructure improvements alone were not sufficient to promote economic growth at the national and 


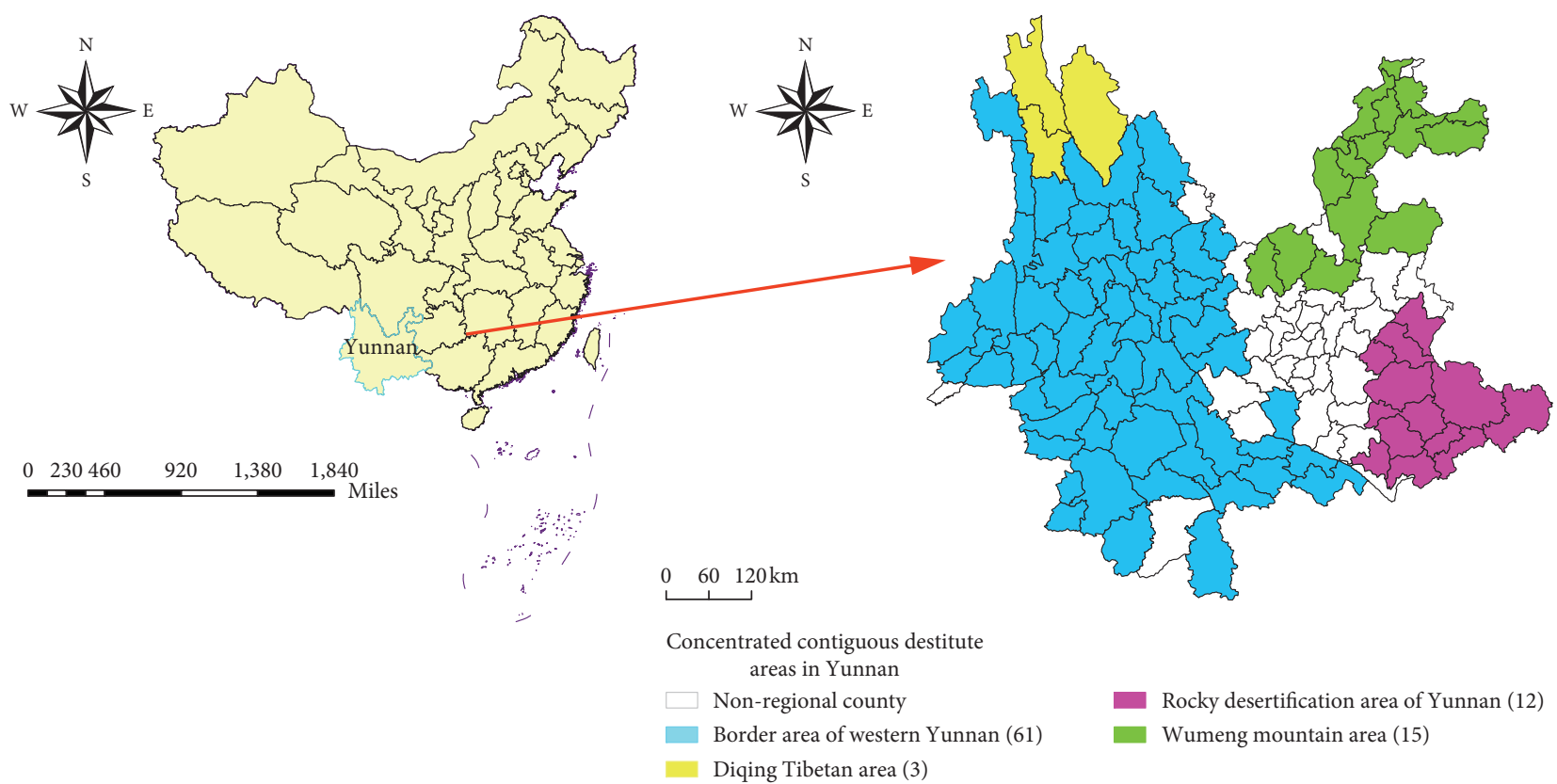

(a)

(b)

FIgURE 1: Location of the concentrated contiguous destitute areas of Yunnan, China.

regional levels in China [44]. Most of the above reviewed studies were case based and only show a certain specific pathway that explains the transport-region economic relationship.

These studies provide critical references for theorizing the transport-region economic relationship. Nevertheless, the studies on this subject are not comprehensive enough in geographical terms and have not covered most of the regions in developing countries where poverty is widespread $[36,45]$, especially in the contiguous poverty-stricken areas. The pathways for the influence of the road infrastructure on the local economy should be very complex. Poverty-stricken areas should be identified in order to compare the existing results of studies in developed regions. However, few efforts have focused on these areas and aspects. Additionally, no specific conceptual framework has been proposed to demonstrate the transport-region economic relationship with regard to road infrastructure construction.

\subsection{Theoretical Framework. A growing body of empirical} literature indicates that road infrastructure plays an important role in regional economic development, and it can generate payoffs for local development. However, there is uncertainty as to how the payoffs come into effect. Perfect road transportation service would positively increase the employment scale and income of poverty-stricken areas, influence the spatial location and layout of the market, and realize the effect of spatial agglomeration, while poor transportation infrastructure service may cause issues within the economic and social welfare system. The effects can be divided into two aspects: one is direct investment drive, and the other is indirect economic spillover. Figure 2 offers a view of the mechanism and processes by which road infrastructure influences economic development and alleviates poverty [46].

On one hand, improving road transportation investment and service can directly reduce the production cost and improve the productivity of relevant industries in poor areas. It is also known as "cost saving effect," which promotes total factors productivity growth (TFP) and the rate of economic growth in the poor areas. At the same time, road infrastructure investment can significantly reduce transport and travel costs, improve the accessibility and convenience of poor areas, and bring about multiplier effect of economic production activities.

On the other hand, the indirect effects of road infrastructure on economic growth and poverty alleviation can be categorized into three aspects: spatial spillover effect, spatial agglomeration and technical diffusion effect, and attraction effect. Road infrastructure has the characteristics of network and externality. Positive spatial spillovers take place when connectivity and accessibility in the surrounding areas are improved, those would then lead to the immigration of knowledge, technology, and resources to surrounding areas and strengthen attraction in the poor regions. In addition, the attraction effect would promote connectivity and improve resource allocation. The three effects and mechanisms influence the evolution and adjustment of regional spatial structure, thus promoting the development of regional economic. The "trickle-down effect" of economic growth can indirectly improve the quality of social services, such as medical care, education, and banking in poor areas and make it easier for the poor to enjoy facilities and services, so as to reduce poverty. 


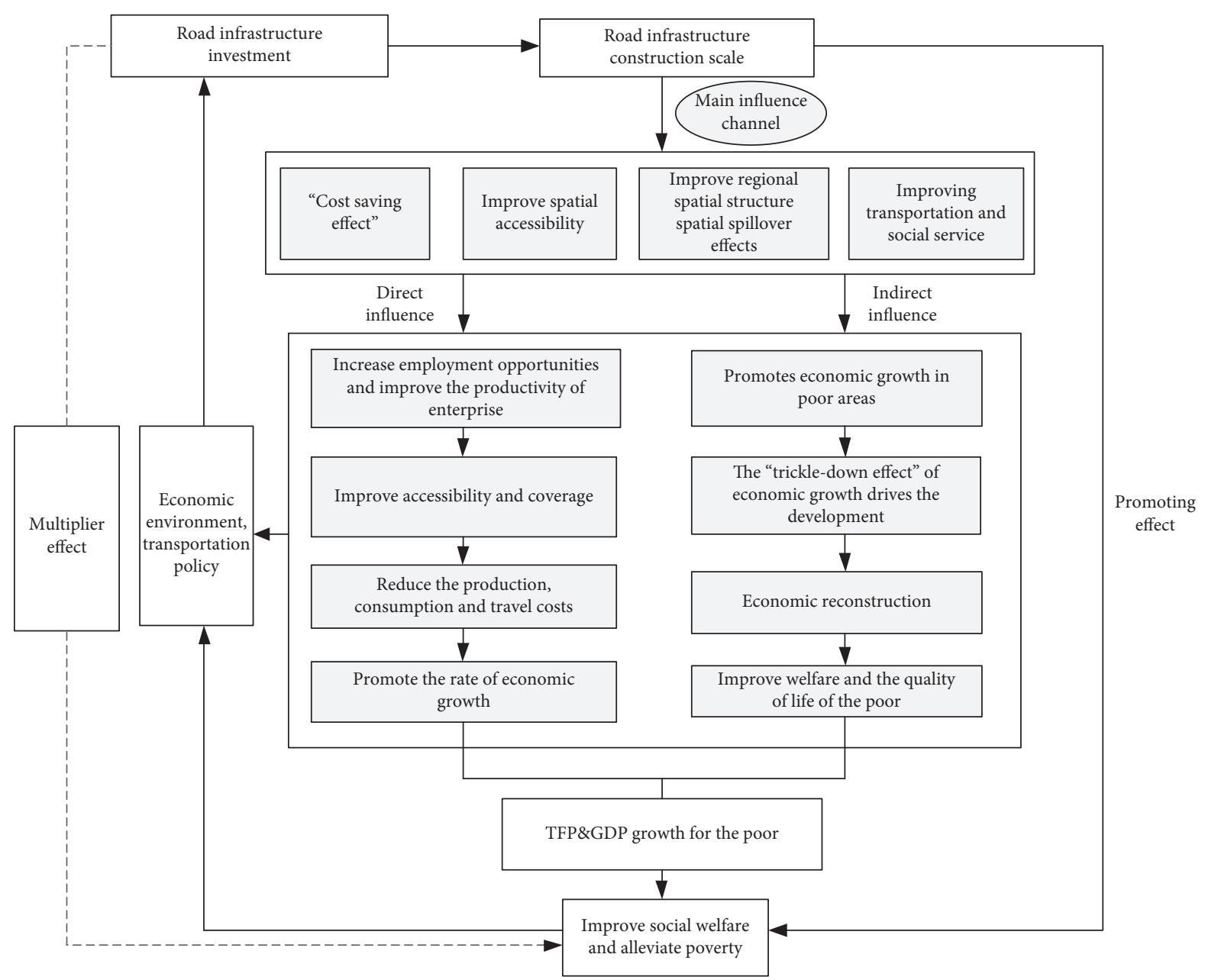

FIgURE 2: Theoretical framework for the influencing pathway between road infrastructure and local economy.

\section{Materials and Methods}

3.1. Data Sources. This paper takes 91 cities/counties in the concentrated contiguous destitute areas of Yunnan province as the research object. The research data are mainly composed of the basic geographic data and the social public service guarantee data as shown in Table 1.

\subsection{Statistical Analysis and Modeling}

3.2.1. Road Infrastructure Assessment Model. Before turning to theoretical and empirical investigation, we made some descriptive statistics on the road infrastructure and poverty incidence in the study area.

Yunnan province, as an underdeveloped region in the west, is located on the Yunnan-Guizhou plateau with complex terrain. Compared with other modes of transportation, the highway network has a large scale and is the leading mode of the comprehensive transportation system of the whole province. In this paper, the configuration of road infrastructure is used to represent the situation of road infrastructure in the whole province. Considering the practicability of the data, four indexes of highway mileage, highway mileage, highway proportion, and the number of passenger stations above grade 2 are selected to construct the configuration status of road infrastructure at county level. In order to avoid the influence of subjective factors, the evaluation model of road infrastructure based on entropy weight method is constructed. The model expression is as follows:

$$
\begin{aligned}
z_{i j} & =\frac{x_{i j}}{\sum_{i=1}^{n} x_{i j}}, \\
e_{j} & =-\frac{1}{\ln m} \sum_{i=1}^{m} z_{i j} \ln z_{i j}, \\
d_{j} & =1-e_{j}, \\
w_{j} & =\frac{d_{j}}{\sum_{i=1}^{n} d_{j}}, \\
\mathrm{HIC}_{i} & =\sum_{j=1}^{n} w_{j} z_{i j} .
\end{aligned}
$$

In this formula, $x_{i j}$ is the value of the $j$-th index of the $i$-th research unit; $z_{i j}$ is the normalized value of the $j$-th index of the $i$-th research unit; $m$ indicates the total number of research units; $e_{j}$ is the entropy value of index $j ; d_{j}$ is the entropy redundancy of index $j ; w_{j}$ indicates the weight of index $j ; n$ is 
TABLE 1: Data sources.

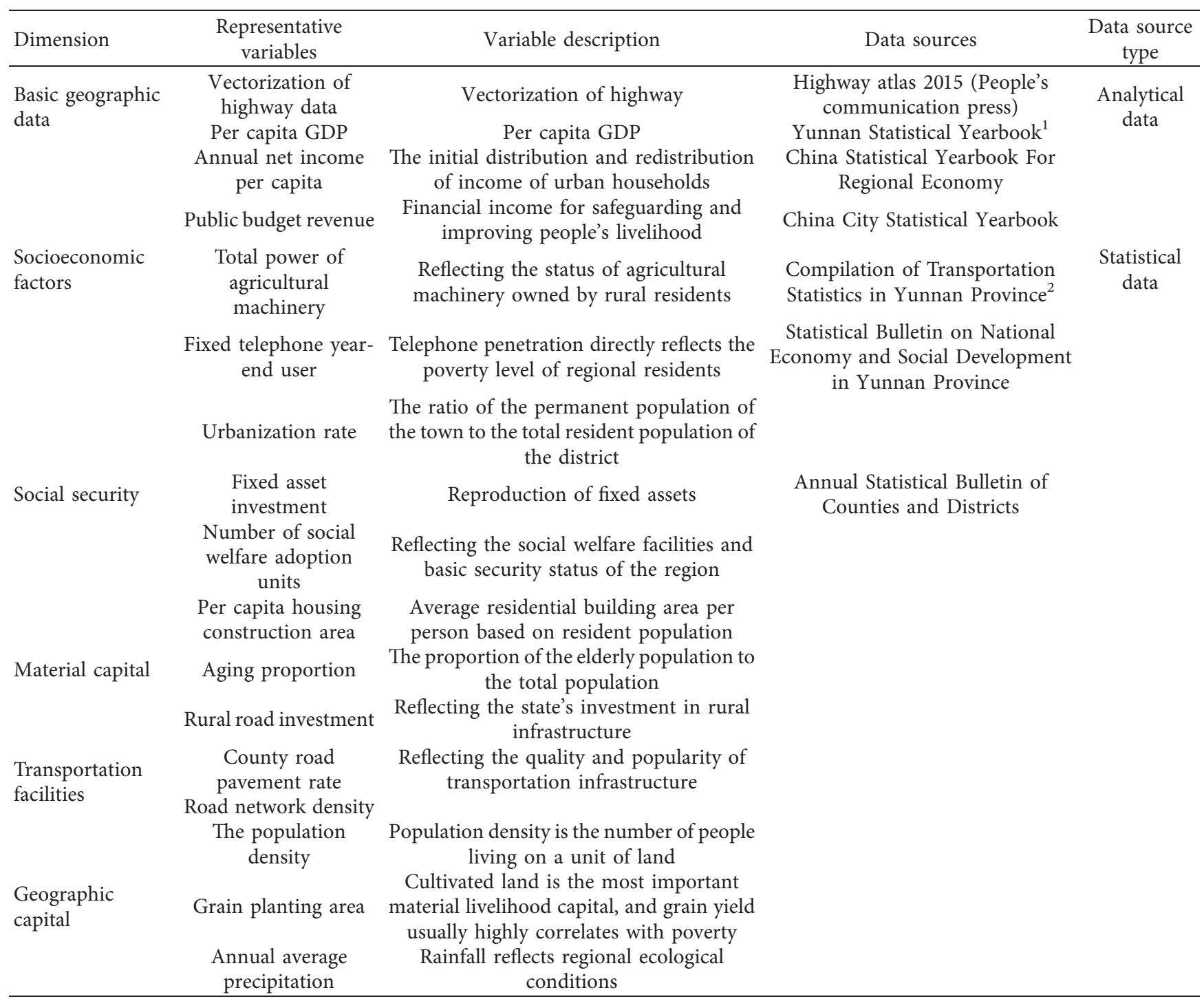

${ }^{1}$ Yunnan Statistical Yearbook (1988-2017), Yunnan Provincial Bureau of Statistics (2000-2017), Yunnan Provincial. ${ }^{2}$ Yunnan Province Traffic Statistics Compilation (2000-2017), Yunnan Provincial Department of Transportation (2000-2017).

the total number of evaluation indicators; and $\mathrm{HIC}_{i}$ is the road infrastructure grade score of the research unit $i$.

3.2.2. Coupling Harmonious Degree Model. In order to obtain the level of coordination between road infrastructure and poverty rate at the county scale, a coupling coordination degree model was constructed. The model expression is as follows:

$$
\begin{aligned}
W_{i} & =2 \times\left[\frac{K_{i} \times H_{i}}{\left(K_{i}+H_{i}\right)^{2}}\right]^{(1 / 2)}, \\
X_{i} & =\sqrt{W_{i} \times Q_{i}}, \\
Q_{i} & =\alpha K_{i}+\beta H_{i} .
\end{aligned}
$$

In this formula, $W_{i}$ denotes the coupling degree of the area and county $i ; K_{i}$ and $H_{i}$ denote the road infrastructure grade score and poverty incidence rate of county $i ; X_{i}$ indicates the coupling coordination degree of the area and county $i$; $Q_{i}$ indicates the comprehensive coordination index of the score of road infrastructure grade and poverty incidence in the area and county $i$; and $\alpha, \beta$ are the undetermined coefficients, which are generally 0.5 .

3.2.3. Structural Equation Model. The economic impact of transportation infrastructure investment is the most widely discussed issue, and various methodologies have been applied to address this problem. The most common approaches are the production function model and the cost function approach. [47-49]. Although they are widely used, there are still some problems. The production function model does not account for simultaneity or any noncontemporaneous effects among the different variables. Although the cost 
function approach is able to show whether transportation investment can contribute to economic development and how this effect is realized, it also has its own shortcomings of spurious correlation, nonstationary, and noncointegration [46]. Compared with the above-mentioned approaches, structural equation model (SEM) is flexible and practical; it can be preperceived by correspondence canonical analysis. Therefore, SEM is employed to investigate the transportregion economic relationship, as well as the mediating factors. We perform the F test for variance homogeneity, the Shapiro-Wilk test for normality, and the standard deviation model for standardization. The maximum likelihood was employed to establish the SEMs for the concentrated contiguous destitute areas of Yunnan. To evaluate the model performance, we refer to several well established indicators, including the chi-square $\left(\chi^{2}\right)$ test, the goodness-of-fit index (GFI), the comparative fit index (CFI), the root mean squared error of approximation (RMSEA), and the adjusted goodness-of-fit index (AGFI). Model validity is evaluated by the critical ratio $(\mathrm{CR})$ and item reliability $\left(R^{2}\right)$. Acceptable values for the two indicators are recommended as $|C R|>2.0$ and $R^{2}>0.5$. Relationships among different variables are interpreted based on the standardized coefficients [9].

The initial structural equation model contains five latent variables and 30 observed variables; according to the test results, the structural equation model established in this paper is overidentified. The revised model includes 14 indicators reflecting the county's natural geographical conditions, resource endowments, traffic location, education level of residents, welfare protection, and social and economic development level. The model introduced potential variables on the basis of considering the path relationship between exogenous variables and endogenous variables.

$$
y=B y+\Gamma x+\zeta
$$

where $y$ is the exogenous latent variables, represented by a vector composed of endogenous indicators; $x$ is the endogenous latent variables, represented by a vector composed of exogenous indicators; $B$ is the coefficient of interaction between endogenous latent variables; $\Gamma$ is the effect coefficient of exogenous latent variables on endogenous latent variables (path coefficient); and $\zeta$ is the residual vector of the structural equation, reflecting the unexplained part of $y$ in the equation.

The road infrastructure is based on structural equation model to construct poverty reduction path and the strength of research methods, mainly through path graph and effect value to analyze road infrastructure construction investment and how it affects the economic growth and poverty reduction, as well as how road infrastructure indirectly contributes to poverty reduction through other industries and capital, to characterize the spatial spillover effects of the road infrastructure and the effectiveness of comprehensive poverty alleviation.

\section{Results}

4.1. Analysis of Spatial Characteristics of Road Infrastructure and Poverty Incidence. Based on the data of highway infrastructure and poor population, formula (1) and poverty rate formula are used to calculate the road infrastructure grade score and poverty incidence in the research area, and ArcGIS spatial analysis technology is used to describe its spatial characteristics. The detailed analysis results are presented in Figures 3 and 4.

(1) Unbalanced distribution and unreasonable proportional structure of road network in Yunnan province were found. The rural road coverage rate is obviously insufficient, resulting in the low level of the overall road network.

(2) Yuanjiang valley and the south section of Yunling mountain, taken as the boundary, present a high-low distribution "transition zone" of road infrastructure from Deqin County to Hekou County, with east Yunnan and central Yunnan high-value areas in the east, lowvalue areas in the border area of Western Yunnan, and the high-value area and low-value area showing the characteristics of strong spatial agglomeration.

(3) The poverty in the study area presents a strong spatial heterogeneity. The areas with high poverty rate are mainly concentrated in the Diqing Tibetan area and the Wumeng Mountain area, forming "double cores" of different sizes.

4.2. Spatial Coupling Results of Road Infrastructure and Poverty Rates. On the basis of obtaining the characteristics of road infrastructure and poverty, formulas (2) and (3) are used to calculate the coupling and coordination value of road infrastructure and poverty rate in the district counties, and the coupling and coordination value is divided into five spatial relations according to the calculation results, as shown in Figure 5.

(1) About $70 \%$ of the district counties' road infrastructure and poverty rate are in a state of spatial coupling imbalance. Among them, as one of the "three districts and three states" in the deep poverty areas, Nujiang belongs to a typical type of maladjustment and common loss. Influenced by terrain, geological conditions, resource endowment, and other factors, the lag of road infrastructure and deep poverty are intertwined for a long time.

(2) The coordinated synchronous type is mainly distributed along the transportation network. For example, the continuous promotion of the construction of Kunming-Qiaojia expressway and Panzhihua-Zhaotong-Bijie-Zunyi railway will speed up the gradual improvement of the comprehensive transportation system of Qiaojia and Daguan Counties, and the steady improvement of economic development. The completion and opening of the high-speed railway between Yunnan and Guangxi have driven the rapid development of tourism, characteristic agriculture, and service industry in Maitreya, and the number of employees has increased significantly. 

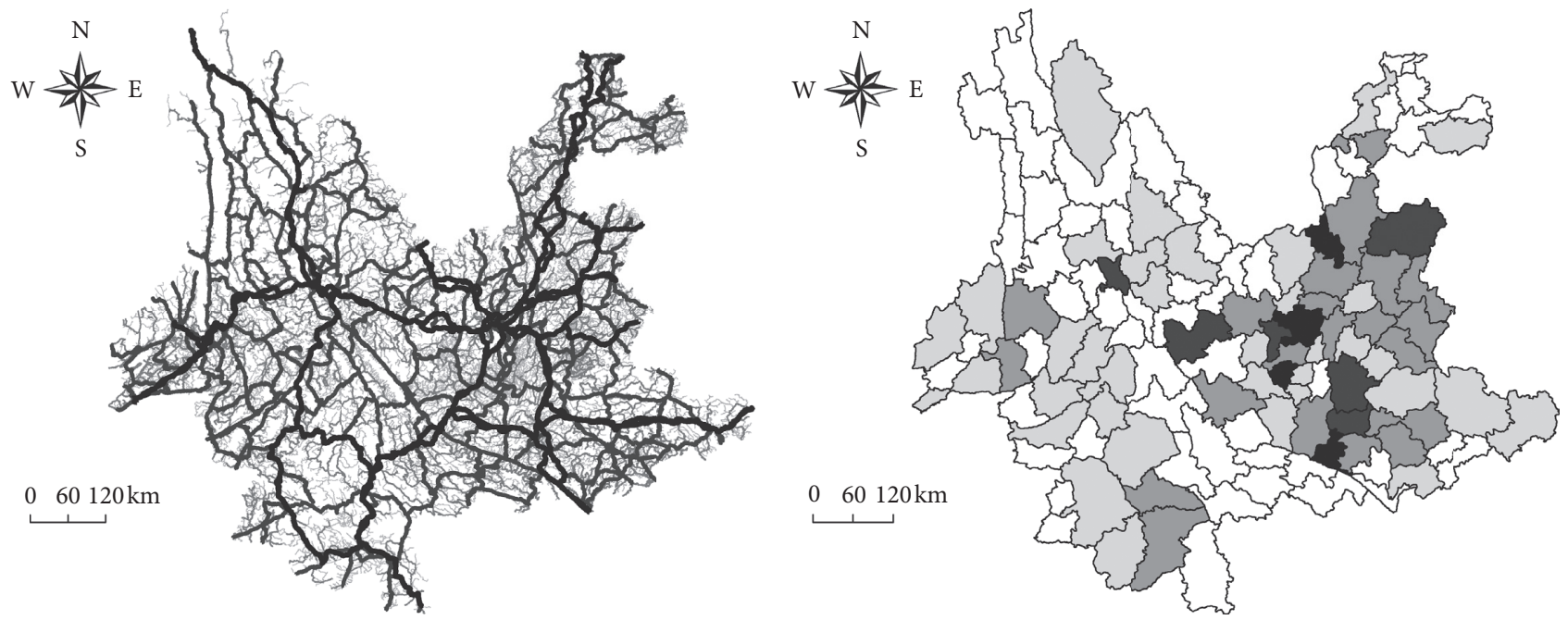

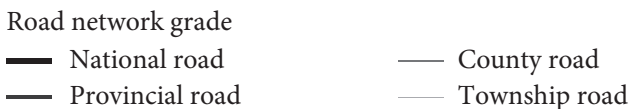

(a)
Grade of highway

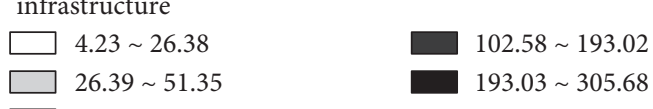

(b)

FIGURE 3: Spatial distribution of road infrastructure network and hierarchy. (a) Road network grade. (b) Road infrastructure assessment.

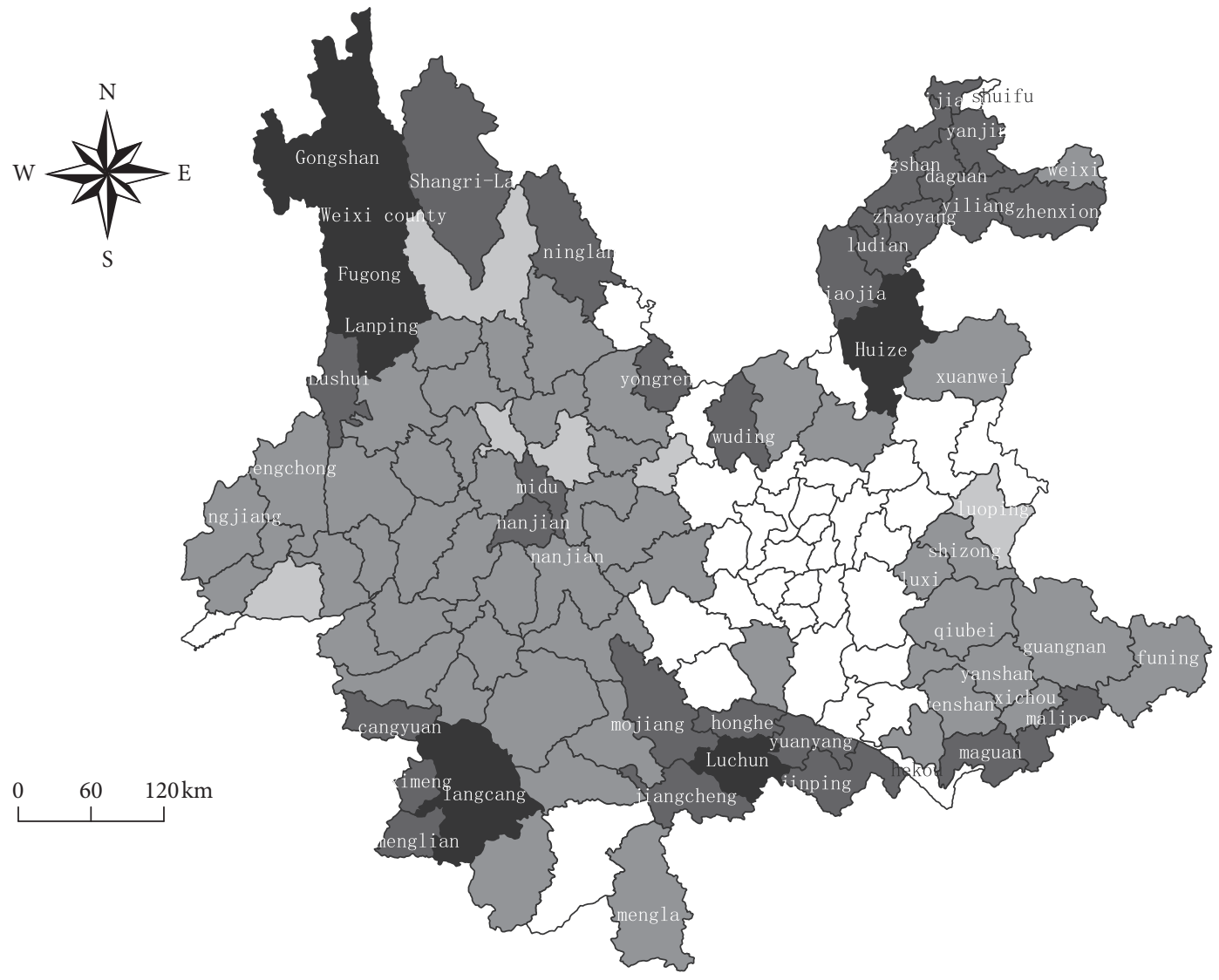

Incidence of poverty in contiguous destitute areas $\square$ Non-district county 


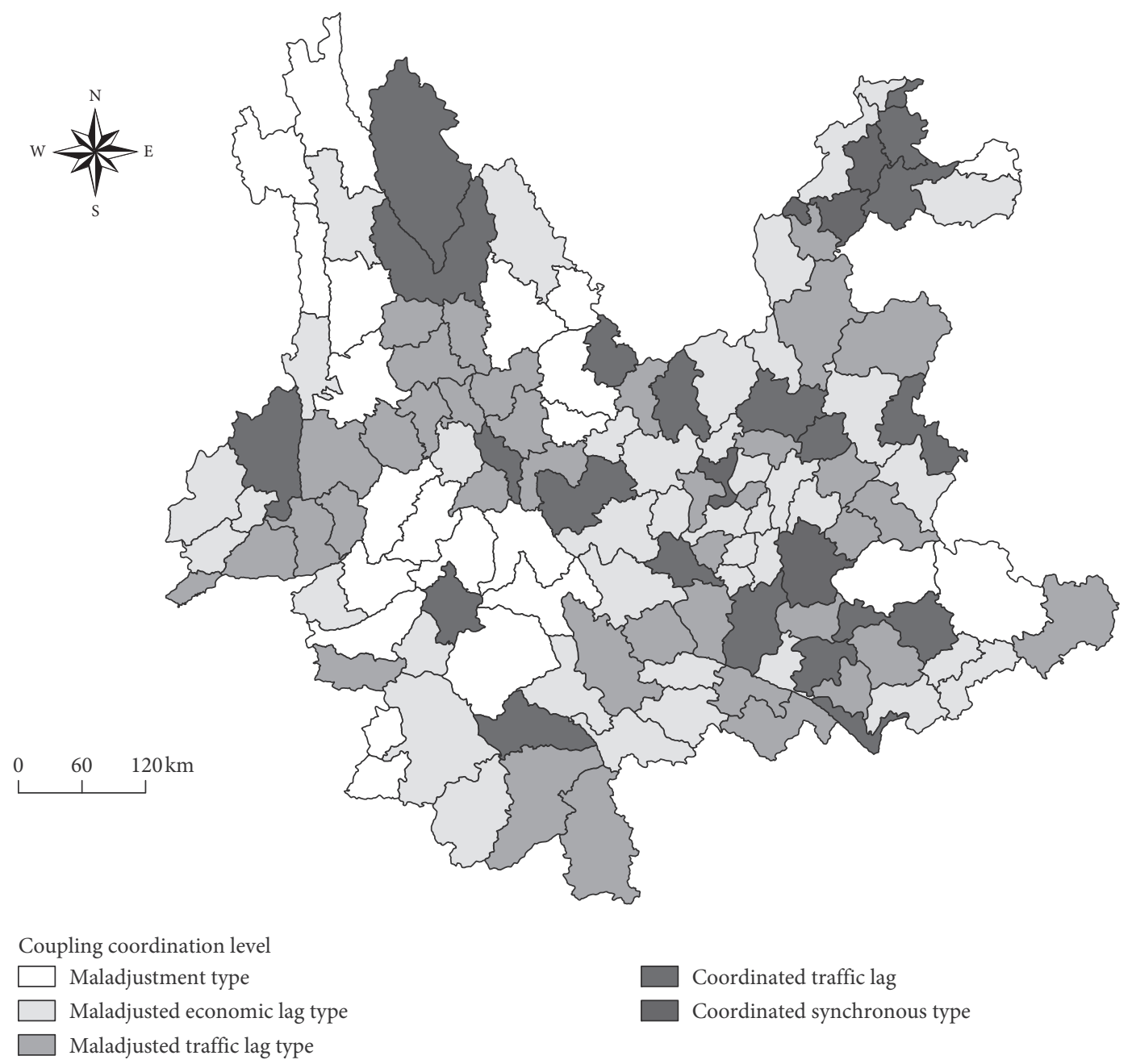

FIGURE 5: Spatial pattern of coupling coordination degree.

4.3. The Path and Intensity of Poverty Reduction on Road Infrastructure. On the basis of determining the coupling and coordination relationship between road infrastructure and poverty rate, the effect of poverty reduction becomes the focus of attention. Furthermore, structural equation model was used to quantify the path and intensity of action of road infrastructure investment and construction on poverty reduction.

The revised model overall fitness test and the optimal model parameter estimation results are shown in Tables 2 and 3. The analysis results show that the test results are generally matched, and the path coefficients in the model basically reach the significance of $1 \%$ level. The following path coefficients are acceptable, and the model variance estimates are all positive and consistent with the level of significance.

In the structural equation model, the path coefficient value reflects the impact of different variables such as road infrastructure, social capital, and geographical capital on poverty reduction. Investment and construction of road infrastructure stimulate the economy to achieve the ultimate goal of reducing poverty through direct or indirect diversification of routes, as shown in Figure 6.
(1) In terms of the direct poverty reduction effect, the road infrastructure investment and construction can directly affect the poverty reduction, with a path coefficient of 0.105 , which is very significant. However, the direct effect is far lower than the indirect poverty reduction effect $(0.830)$ brought by the road infrastructure investment and construction, which affects geographical location, fixed asset investment, secondary and tertiary industries development, and urbanization. This shows that the contribution of transport infrastructure investment and construction to poverty reduction is more indirect in the form of spatial spillover, network attributes, and externality of road infrastructure construction, which play an important role in economic development and poverty reduction. The enlargement of road networks would definitely accelerate capital and resource flow, as well as human movement. Consequently, the local interactions with outside economy are increased. Such interactions are considered critical drivers for economic growth in less developed areas. In particular, inputs from other sectors can be created and increased by road network 
TABLE 2: Evaluation results of the modified model.

\begin{tabular}{|c|c|c|c|c|c|c|c|c|c|}
\hline Statis & $X^{2}$ & df & $X^{2} / \mathrm{df}$ & RMSEA & CFI & NFI & GFI & IFI & AGFI \\
\hline Fitn & - & - & $\begin{array}{c}1<\mathrm{NC}<3 \text {, good } \\
3<\mathrm{NC}<5 \text {, not too bad }\end{array}$ & $\begin{array}{c}\text { RMSEA }<0.5 \text {, good } \\
0.5<\mathrm{NC}<0.8, \text { not too bad }\end{array}$ & $>0.9$ & $>0.9$ & $>0.9$ & $>0.9$ & $>0.9$ \\
\hline & 25 & 75 & 2.826 & 0.484 & 0.5 & 0. & 0. & 0 . & 0.9 \\
\hline Adaptation judgment & - & - & Good & Good & Perfect & Perfect & Perfect & Perfect & Perfect \\
\hline
\end{tabular}

TABLE 3: Estimation results of the variable coefficient and significance test.

\begin{tabular}{|c|c|c|c|c|c|c|}
\hline Acting path & Estimate & SE & CR & $P$ & Label & Standardized estimates \\
\hline Material capital <--- road infrastructure & 0.470 & 0.270 & 2.742 & 0.002 & par_21 & 0.323 \\
\hline Geographical capital<--- road infrastructure & 0.020 & 0.002 & 8.843 & $* * *$ & par_29 & 0.669 \\
\hline Social capital $<---$ material capital & 4.697 & 2.485 & 1.980 & 0.039 & par_13 & 0.458 \\
\hline Social capital<--- geographical capital & 385.159 & 64.215 & 5.998 & $* * *$ & par_14 & 0.757 \\
\hline Traffic dominance <--- road infrastructure & 1.000 & & & & & 0.804 \\
\hline Highway network density<--- road infrastructure & 0.146 & 0.030 & 4.818 & $* * *$ & par_1 & 0.572 \\
\hline Poverty reduction effect $<---$ material capital & 3599.722 & 3506.741 & 3.027 & $* * *$ & par_18 & 0.263 \\
\hline Poverty reduction effect <--- social capital & 1509.292 & 576.523 & 2.618 & $* *$ & par_19 & 1.132 \\
\hline Poverty reduction effect <--- geographical capital & 7535.539 & 224994.298 & 3.033 & $* * *$ & par_25 & 0.011 \\
\hline Total power of agricultural machinery $<--$ social capital & 1.000 & & & & & 0.702 \\
\hline Revenue from the public budget <---highway network density & 2291.362 & 534.740 & 4.285 & $* * *$ & par_17 & 0.166 \\
\hline Minority share $<---$ transport advantage & 1414.846 & 263.234 & 5.375 & $* * *$ & par_27 & 0.284 \\
\hline Rural road investment $<---$ road infrastructure & 0.053 & 0.017 & 3.201 & $* * *$ & par_2 & 0.230 \\
\hline Per capita housing construction area $<---$ material capital & 1.000 & & & & & 0.163 \\
\hline Number of social welfare adoption units $<---$ material capital & 0.755 & 0.451 & 2.675 & ** & par_3 & 0.213 \\
\hline The proportion of aging $<---$ material capital & 0.006 & 0.003 & 2.986 & $* * *$ & par_4 & 0.412 \\
\hline Grain production $<--$ geographical capital & 1558.083 & 1032.655 & 2.809 & $* * *$ & par_5 & 0.131 \\
\hline Urbanization rate $<---$ poverty reduction effect & 0.007 & 0.001 & 7.897 & $* * *$ & par_6 & 0.615 \\
\hline Fixed-line users at the end of the year $<---$ social capital & 699.746 & 114.571 & 6.108 & $* * *$ & par_7 & 0.401 \\
\hline Per capita GDP <---poverty reduction effect & 1.000 & & & & & 0.702 \\
\hline Revenue from the public budget $<---$ social capital & 0.000 & 0.000 & 20.600 & $* * *$ & par_9 & 1.109 \\
\hline Fixed assets investment $<---$ social capital & 8.685 & 0.681 & 12.760 & $* * *$ & par_20 & 0.959 \\
\hline Population density<--- geographical capital & 1.000 & & & & & 0.726 \\
\hline $\begin{array}{l}\text { The proportion of aging }<--- \text { total power of agricultural } \\
\text { machinery }\end{array}$ & 0.000 & 0.000 & 6.899 & $* * *$ & par_22 & 0.449 \\
\hline $\begin{array}{l}\text { Per capita housing construction area }<--- \text { proportion of ethnic } \\
\text { minorities }\end{array}$ & 0.001 & 0.000 & 11.120 & $* * *$ & par_28 & 0.627 \\
\hline
\end{tabular}

"<---" indicates the orientation in which the utility occurred; ${ }^{* *} P<0.01,{ }^{* * *} P<0.001$.

construction, and the multiplier economic effect is subsequently stimulated. This finding suggests that the realization of the effect of road infrastructure on economic growth needs the synergy of institutional environment improvement, human capital improvement, science and education technology level improvement, and other factors. When analyzing the causes of economic growth, multidimensional factors need to be taken into account in order to improve the social welfare and reduce transport poverty in poverty-stricken areas. This discovery is in line with the past literature reporting that the spatial structure evolution was closely linked with road infrastructure construction $[50,51]$.

(2) In terms of the indirect poverty reduction effect, there is a significant difference in the path and degree of the road infrastructure to promote economic growth and ultimately reduce poverty. This paper mainly works through five poverty reduction path modes of road infrastructure. Among them, " road infrastructure $\longrightarrow$ social capital $\longrightarrow$ poverty reduction effect" has the highest path coefficient (0.740), and the contribution of fixed asset investment and public budget income to social capital is 0.959 and 1.109, respectively, which are higher than other poverty reduction factors.

(3) Road infrastructure investment and construction can guide economic development and reduce poverty by acting on geographic capital, material capital and social capital. The overall action coefficient is 0.740 , which is higher than the poverty reduction effect of the two paths of "road infrastructure $\longrightarrow$ geographic capital/material capital $\longrightarrow$ poverty reduction effect". The path coefficient of "road infrastructure $\longrightarrow$ geographical capital $\longrightarrow$ social capital $\longrightarrow$ poverty reduction effect" is 0.573 , which is higher than that of "road infrastructure $\longrightarrow$ material capital $\longrightarrow$ social capital $\longrightarrow$ poverty reduction effect" (0.167). 


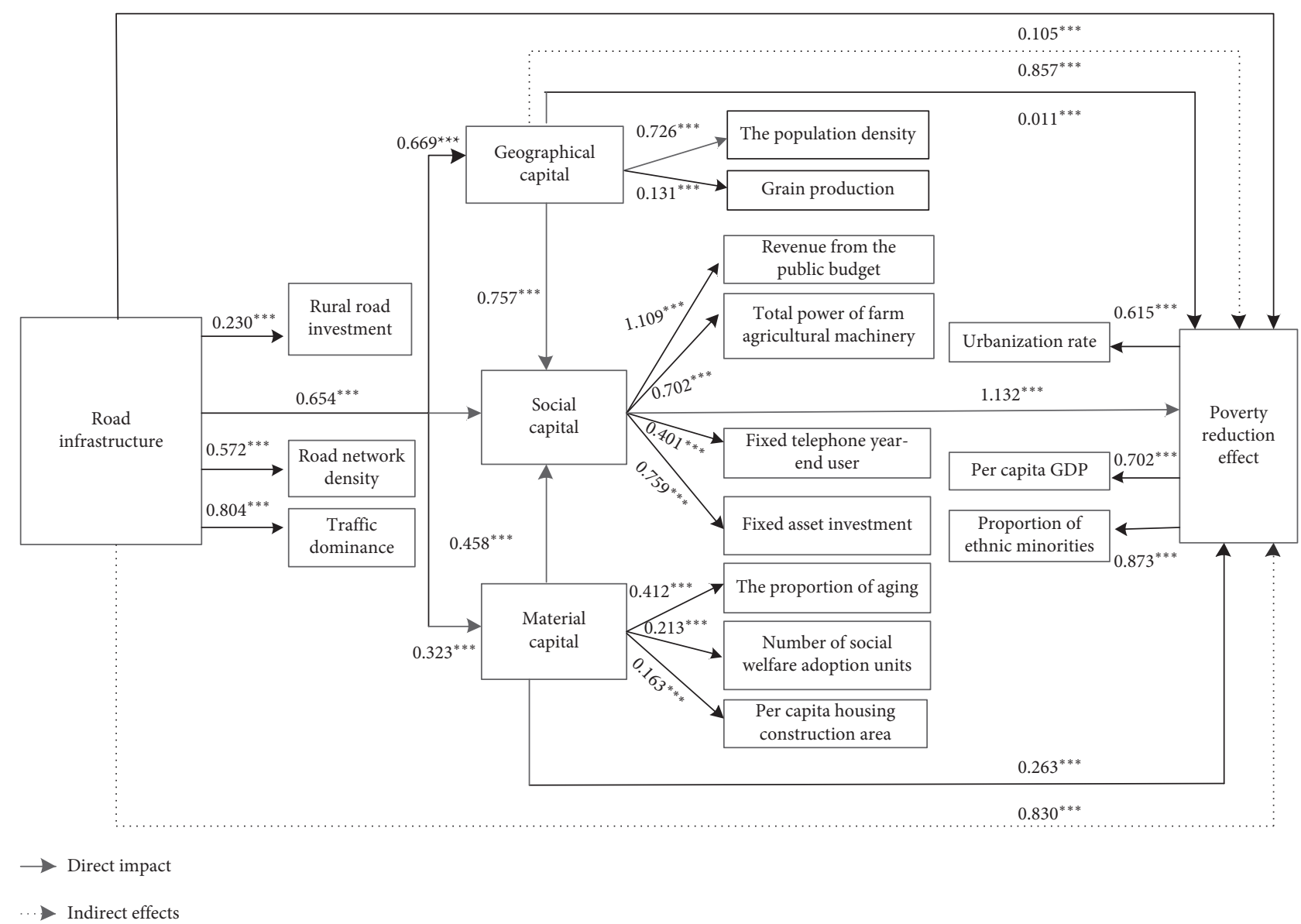

FIGURE 6: Estimation results of the SEM for poverty alleviation path of road infrastructure.

(4) Either the investment and construction of transportation infrastructure itself or the associated capital and industrial development brought by it are obviously conducive to economic growth and employment of the poor. Taking the construction of highway transportation investment as an example, in the link of road production and construction, highway transportation investment and construction can attract a large amount of labor to increase nonagricultural employment opportunities, reduce transportation costs, and improve production efficiency. In the link of traffic operation, highway traffic investment and construction can promote the location choice, productivity distribution, and production factor agglomeration of enterprises.

\section{Conclusion and Discussion}

5.1. Conclusion. In this paper, the evaluation model of transportation infrastructure based on entropy weight method and a coupling coordination degree model are established, obtaining the spatial characteristics and spatial coupling results of road infrastructure and poverty incidence. On that basis, a structural equation model has been established to describe the relationships between the variables, and the relationship between transportation investment and regional economic growth is estimated. Based on the results of empirical study, the following key conclusions are drawn.

(1) The structural equation model confirms the significant effect of road infrastructure investment and construction on economic growth and poverty reduction, but the path and degree of poverty reduction are quite different. The direct effect of road infrastructure investment and construction on poverty reduction is far less than the indirect effect, and the diversification path is produced indirectly through the form of spatial spillover. Among the five path models of poverty reduction effects on road infrastructure, "road infrastructure $\longrightarrow$ social capital $\longrightarrow$ poverty reduction effect" has the highest path coefficient of poverty reduction, and the effect of poverty reduction is the best.

(2) The contribution rate of the number of passenger stations above grade 2 and county road pavement rate is higher than those of other traffic indicators, which is the most important poverty reduction factor in the study area.

(3) About $70 \%$ of the district counties' road infrastructure and poverty rate are in a state of spatial coupling imbalance. The coordinated synchronous 
type is mainly distributed along the transportation network.

The research results can provide theoretical and practical basis for the formulation of transportation poverty alleviation strategy, so as to effectively play the leading and supporting role of transportation infrastructure in poverty alleviation and rural revitalization. In order to more comprehensively analyze the impact of transportation supply on economic growth and poverty reduction, based on the theory of spatial equity and the principle of regional deprivation compensation, we put forward the poverty alleviation and optimization strategy of traffic resource allocation in the concentrated contiguous destitute areas from the perspective of spatial equity:

(1) Speeding up the building of a transportation network that connects the poverty-stricken areas with the outside world and the inside world and connects the villages and townships

(2) Innovating ways of providing transportation to help the poor and advancing a new comprehensive approach of transportation poverty alleviation

(3) Developing public-private partnerships (PPP) in various forms and innovating investment and financing mechanisms

Considering this strategic decision-making in the statistical model could produce interesting and useful policy insights.

5.2. Discussion. Transportation infrastructure has complex interactions with regional economic systems. Prior studies indicate that impacts of transportation infrastructure are more pronounced in developing countries, as the prevalence of infrastructure is lower in these countries [52]. This paper builds several models to uncover the contributing factors in mediating the relationships between the road infrastructure and local economy in the concentrated contiguous destitute areas of Yunnan. We found that the established models are efficient in revealing the relationship between the road infrastructure and the less developed places' economy. Previous studies advocate road infrastructure as a primary economic catalyst in less developed areas, as it can increase the accessibility to market, eliminate constraints to social services, and provide employment $[6,7]$. The results for the concentrated contiguous destitute areas of Yunnan are in accordance with earlier findings.

This paper demonstrates that SEM is efficient in our case. However, SEM is not always strong in proving causality. Regional and local policies regarding road infrastructure investment promoting economic growth differ significantly across various regions in different countries; when applying the demonstrated methodology to other areas worldwide, it requires caution and further verification. Though our study advances the understanding of the relationships between the road infrastructure and regional economic, it still has certain shortcomings. First, all the indicators of the article are chosen based on empirical literature review and data availability; subjectivity is unavoidably associated with the selection methods by which the exploratory variables can be selected more scientifically. Second, the SEMs are established by using the maximum likelihood approach in this study. However, whether or not this approach is a methodological advantage remains unproven. Third, this paper examines the concentrated contiguous destitute area at the provincial level; to deepen the understanding of the relationship between the road infrastructure and local economy, future studies should investigate and compare different regions with different levels of development. Fourth, road infrastructure is not the only type of road infrastructure. Since the highway network has a large scale and is the leading mode of the comprehensive transportation system of the Yunnan province, our study does not consider railways and high-speed rails. Some studies have evidenced the effect of high-speed rails on the economic characteristics; consequently, the exclusion of railways may overestimate the empirical findings in this study. Further studies should control the railways and high-speed rails, to isolate the individual effect of road infrastructure on the urban economy.

\section{Data Availability}

The data that used to support the findings of this study are currently under embargo while the research findings are commercialized. Requests for data, 12 months after publication of this article, will be considered by the corresponding author.

\section{Disclosure}

The funders had no role in the design of the study or in the collection and interpretation of the data.

\section{Conflicts of Interest}

The authors declare no conflicts of interest.

\section{Acknowledgments}

This research was supported by the Natural Science Foundation of China under grant nos. 71904068 and 41501174, the Science and Technology Project of Guangzhou City under grant no. 201804010466, the Natural Science Foundation of Zhejiang Province under grant no. LY18G030021, and the Fundamental Research Funds for the Central Universities under grant no. 2019MS120.

\section{References}

[1] R. Kanbur, "Economic policy, distribution and poverty: the nature of disagreements," World Development, vol. 29, no. 6, pp. 1083-1094, 2001.

[2] D. Narayan, R. Patel, K. Schafft et al., Voices of the Poor Can Anyone Hear Us?, Oxford University Press for the World Bank, New York, NY, USA, 2000.

[3] R. Vakis, J. Rigolini, and L. Lucchetti, Left behind: Chronic Poverty in Latin America and the Caribbean, World Bank publication, Washington, DC, USA, 2016. 
[4] ADB (Asian Development Bank), Sustainable Transport Initiative: Operational Plan, ADB, Philippines, PA, USA, 2010.

[5] Y. Liu, Z. Liu, and R. Jia, "DeepPF: a deep learning based architecture for metro passenger flow prediction," Transportation Research Part C: Emerging Technologies, vol. 101, pp. 18-34, 2019.

[6] R. Asomani-Boateng, R. J. Fricano, and F. Adarkwa, "Assessing the socio-economic impacts of rural road improvements in ghana: a case study of transport sector program support (II)," Case Studies on Transport Policy, vol. 3, no. 4, pp. 355-366, 2015.

[7] M. Iacono and D. Levinson, "Mutual causality in road network growth and economic development," Transport Policy, vol. 45, pp. 209-217, 2015.

[8] S. E. Polzin, "Transportation/land-use relationship: public transit's impact on land use," Journal of Urban Planning and Development, vol. 125, no. 4, pp. 135-151, 1999.

[9] H. You, "Agricultural landscape dynamics in response to economic transition: comparisons between different spatial planning zones in Ningbo region, China," Land Use Policy, vol. 61, pp. 316-328, 2017.

[10] S. Su, Q. Zhang, J. Pi, C. Wan, and M. Weng, "Public health in linkage to land use: theoretical framework, empirical evidence, and critical implications for reconnecting health promotion to land use policy," Land Use Policy, vol. 57, pp. 605-618, 2016.

[11] M. Wachs and T. G. Kumagai, "Physical accessibility as a social indicator," Socio-Economic Planning Sciences, vol. 7, no. 5, pp. 437-456, 1973.

[12] S. Hanson and P. Hanson, "Gender and urban activity patterns in uppsala, Sweden," Geographical Review, vol. 70, no. 3, pp. 291-299, 1980.

[13] A. Armstrong-Wrigh, Urban Transit Systems, World Bank Technical Papers, Washington, DC, USA, 1986.

[14] D. A. Aschauer, "Is public expenditure productive?" Journal of Monetary Economics, vol. 23, no. 2, pp. 177-200, 1989.

[15] D. A. Aschauer, "Does public capital crowd out private capital?" Journal of Monetary Economics, vol. 24, no. 2, pp. 171-188, 1989.

[16] D. A. Aschauer, "Public investment and productivity growth in the group of seven," Journal of Monetary Economics, vol. 13, no. 5, pp. 17-25, 1989.

[17] C. A. Gannon and Z. Liu, Poverty and Transport, World Bank Publications, Washington, DC, USA, 1997.

[18] M. G. Boarnet, "Spillovers and the locational effects of public infrastructure," Journal of Regional Science, vol. 38, no. 3, pp. 381-400, 1998.

[19] G. Porter, "Transport services and their impact on poverty and growth in rural sub-saharan africa: a review of recent research and future research needs," Transport Reviews, vol. 34, no. 1, pp. 25-45, 2014.

[20] R. Benevenuto and B. Caulfield, "Poverty and transport in the global south: an overview," Transport Policy, vol. 79, pp. 115-124, 2019.

[21] A. Church, M. Frost, and K. Sullivan, "Transport and social exclusion in London," Transport Policy, vol. 7, no. 3, pp. 195-205, 2000.

[22] J. Farrington and C. Farrington, "Rural accessibility, social inclusion and social justice: towards conceptualisation," Journal of Transport Geography, vol. 13, no. 1, pp. 1-12, 2005.

[23] N. Cass, E. Shove, and J. Urry, "Social exclusion, mobility and access," The Sociological Review, vol. 53, no. 3, pp. 539-555, 2005.
[24] N. R. Velaga, M. Beecroft, J. D. Nelson, D. Corsar, and P. Edwards, "Transport poverty meets the digital divide: accessibility and connectivity in rural communities," Journal of Transport Geography, vol. 21, pp. 102-112, 2012.

[25] K. Lucas, “Transport and social exclusion: where are we now?" Transport Policy, vol. 20, pp. 105-113, 2012.

[26] ITF (International Transport Forum), "Income inequality, social inclusion and mobility," Roundtable Report, vol. 164, p. 200, 2017.

[27] K. Lucas, G. Mattioli, E. Verlinghieri, and A. Guzman, "Transport poverty and its adverse social consequences," Proceedings of the Institution of Civil Engineers - Transport, vol. 169, no. 6, pp. 353-365, 2016.

[28] T. Litman, "Measuring transportation: traffic, mobility and accessibility," Institute of transportation engineers, vol. 73, no. 10, p. 28, 2003.

[29] Z. Liu, S. Wang, K. Huang, J. Chen, and Y. Fu, "Practical taxi sharing schemes at large transport terminals," Transportmetrica B: Transport Dynamics, vol. 7, no. 1, pp. 596-616, 2019.

[30] X. Qu, Y. Yu, M. Zhou et al., "Jointly dampening traffic oscillations and improving energy consumption with electric, connected and automated vehicles: a reinforcement learning based approach," Applied Energy, vol. 257, pp. 1-11, 2020.

[31] J. Luo, L. Tian, L. Luo, H. Yi, and F. Wang, "Two-step optimization for spatial accessibility improvement: a case study of health care planning in rural China," BioMed Research International, vol. 2017, Article ID 2094654, 12 pages, 2017.

[32] R. C. Nesbitt, S. Gabrysch, A. Laub et al., "Methods to measure potential spatial access to delivery care in low- and middleincome countries: a case study in rural Ghana," International Journal of Health Geographics, vol. 13, no. 1, p. 25, 2014.

[33] D. J. Weiss, A. Nelson, H. S. Gibson et al., "A global map of travel time to cities to assess inequalities in accessibility in 2015," Nature, vol. 553, no. 7688, pp. 333-336, 2018.

[34] A. Iimi, A. K. F. Ahmed, E. C. Anderson et al., New Rural Access Index: Main Determinants And Correlation To Poverty (English), World Bank Publication, Washington, DC, USA, 2016.

[35] A. K. Sarkar and D. Ghosh, "Integrated rural accessibility planning (IRAP)," Progress in Development Studies, vol. 8, no. 3, pp. 241-259, 2008.

[36] R. H. M. Pereira, T. Schwanen, and D. Banister, "Distributive justice and equity in transportation," Transport Reviews, vol. 37, no. 2, pp. 170-191, 2017.

[37] P. Jiwattanakulpaisarn, R. B. Noland, and D. J. Graham, "Causal linkages between highways and sector-level employment," Transportation Research Part A: Policy and Practice, vol. 44, no. 4, pp. 265-280, 2010.

[38] N. Yu, G. de Roo, M. de Jong, and S. Storm, "Does the expansion of a motorway network lead to economic agglomeration? evidence from China," Transport Policy, vol. 45, pp. 218-227, 2016.

[39] G. M. Ahlfeldt, K. Moeller, and N. Wendland, "Chicken or egg? The PVAR econometrics of transportation," Journal of Economic Geography, vol. 15, no. 6, pp. 1169-1193, 2015.

[40] S. Bougheas, P. O. Demetriades, T. P. Mamuneas et al., "Infrastructure, specialization, and economic growth," $\mathrm{Ca}$ nadian Journal of Economics/Revue Canadienne d'Economique, vol. 33, no. 2, pp. 506-522, 2000.

[41] M. A. Beyzatlar, M. Karacal, and H. Yetkiner, "Grangercausality between transportation and GDP: a panel data approach," Transportation Research Part A: Policy and Practice, vol. 63, pp. 43-55, 2014. 
[42] G. Chi, "The impacts of highway expansion on population change: an integrated spatial approach," Rural Sociology, vol. 75, no. 1, pp. 58-89, 2010.

[43] J. Guo, J. Guo, and J. Xia, "Econometrical investigation on infrastructure investment and economic development in China: a case study using vector autoregression approach," KSCE Journal of Civil Engineering, vol. 15, no. 3, pp. 561-567, 2011.

[44] N. Yu, M. De Jong, S. Storm, and J. Mi, "Transport infrastructure, spatial clusters and regional economic growth in China," Transport Reviews, vol. 32, no. 1, pp. 3-28, 2012.

[45] International Fund for Agricultural Development, Rural Poverty Report, International Fund for Agricultural Development, Rome, Italy, 2011.

[46] X. Jiang, X. He, L. Zhang, H. Qin, and F. Shao, "Multimodal transportation infrastructure investment and regional economic development: a structural equation modeling empirical analysis in China from 1986 to 2011," Transport Policy, vol. 54, no. 2, pp. 43-52, 2017.

[47] J. L. Fan and B. L. Bai, "Impact on economic growth of infrastructure capital: estimate using CES production function method," Economic, vol. 11, pp. 10-13, 2004.

[48] W. Qi, Y. Wang, Y. Bie, and J. Ren, "Prediction model for bus inter-stop travel time considering the impacts of signalized intersections," Transportmetrica A: Transport Science, vol. 02, pp. 1-19, 2020.

[49] Y. Bie, X. Xiong, Y. Yan, and X. Qu, "Dynamic headway control for high-frequency bus line based on speed guidance and intersection signal adjustment," Computer-Aided Civil and Infrastructure Engineering, vol. 35, no. 1, pp. 4-25, 2020.

[50] T. T. Ting and Y. Edward, "Transportation and economic growth in China: a heterogeneous panel cointegration and causality analysis," Journal of Transportation Geography, vol. 73, pp. 120-130, 2018.

[51] H. Li, Y. Liu, and K. Peng, "Characterizing the relationship between road infrastructure and local economy using structural equation modeling," Transport Policy, vol. 61, pp. 17-25, 2018.

[52] D. Banister and J. Berechman, Transport Investment and Economic Development, UCL Press, London, UK, 2000. 